\title{
Novel Coronavirus and the Wastewater Treatment Plants Workers
}

\author{
Sheida Atashkar (iD) ${ }^{1}$, Tooraj Massahi (iD) ${ }^{2,3,{ }^{*}}$ and Mohammad Jasimi (iD) ${ }^{3}$ \\ ${ }^{1}$ School of Public Health and Safety, Shahid Beheshti University of Medical Science, Tehran, Iran \\ ${ }^{2}$ Department of Environmental Health Engineering, School of Public Health, and Research Center for Environmental Determinants of Health (RCEDH), Health Institute, \\ Kermanshah University of Medical Sciences, Kermanshah, Iran \\ ${ }^{3}$ Student Research Committee, School of Public Health, Kermanshah University of Medical Sciences, Kermanshah, Iran \\ "Corresponding author: Student Research Committee, Kermanshah University of Medical Sciences, Kermanshah, Iran. Email: toorajmassahi@gmail.com
}

Received 2021 June 24; Revised 2021 August 23; Accepted 2021 August 25.

Keywords: COVID-19, Workers, Wastewater, WWTPs, SARS-CoV-2

\section{Introduction}

Since December 2019, following the emergence of severe acute respiratory syndrome coronavirus 2 (SARS-CoV2) in Wuhan, China, the world has faced a horrifying pandemic scenario that causes severe respiratory infections (1). Although it is believed that SARS-CoV-2 is mainly respiratory in nature and is transferred from person to person through exposure to respiratory aerosol/droplets from infected patients, it has been currently reported that both viable SARS-CoV-2 and fragments of viral RNA can be transmitted through feces and other body excretions of infected people, such as urine and saliva, to the sewage collection network and eventually to wastewater treatment plants (WWTPs) (2). Several studies are available on the molecular detection of SARS-CoV-2 in municipal WWTPs in a number of countries (3-5). SARS-CoV-2 RNA in wastewater can be a health concern for workers at WWTPs and poses the question of the possible risk of transmission of this virus by wastewater (5). Information and documents on the persistence and the state of SARS-CoV-2 in raw wastewater and subsequently WWTPs are critical, specifically to understand the potential risks to exposed populations because the wastewater treatment process requires the participation of a lot of workers, operators, transporters, and engineers $(5,6)$, and the possibility of an occupational health risk associated with SARS-CoV-2 should be addressed (2).

\section{Arguments}

$\mathrm{Wu}$ et al. have recently suggested about 100 SARSCoV-2 particles per $\mathrm{mL}$ of wastewater from a major urban treatment facility in Massachusetts (USA) (7). Workers in WWTPs engage in routine activities such as manual cleaning of large screens, sampling, and chemical analysis, in- spection of various processes, and control of sludge dehydration (8). In WWTPs the potential for transmission of SARS-CoV-2 has many consequences because SARS-CoV2 do not reproduce in the environment, and transportation through the water cycle increases the possibility of their persistent presence in municipal wastewater. As a result, particularly in WWTP sites with inadequate sanitary infrastructure, there is an alarming potential for transmission, likely from aerosols and airborne particulates to people and workers who are exposed to wastewater at WWTPs (8).

Environmental factors (e.g., solids, pollutants, temperature, and $\mathrm{pH}$ ) influence the fate of SARS-CoV-2 in WWTPS (9). The World Health Organization (WHO) has stated that SARS-CoV-2 will likely be deactivated much more rapidly than known waterborne viruses and survives only two days in dechlorinated tap water and hospital wastewater at $20^{\circ} \mathrm{C}(10)$. Moreover, it has been shown that the molecular weight of substances soluble in wastewater can affect the survival of the virus (11), and the information about the effect of $\mathrm{pH}$ on coronavirus survival is lacking (10). The various units of the treatment plant are not equipped with barriers to prevent splashing the wastewater and other collective protective equipment (CPE) (8) because some WWTP processes produce aerosols capable of transmitting SARSCoV-2 and posing a risk to the health of exposed workers (12). Studies have shown SARS-CoV-2 is infective with aerosols for 16 hours (13). This new problematic situation may be even more dangerous, especially in less developed countries, where occupational exposure of WWTPs workers may be of greater concern, due to the protocols for performing CPE and personal protective equipment (PPE) is not as rigorous as in industrialized countries.

Timely and accurate COVID-19 occupational risk assess- 
ment in WWTPs parts is required, and sanitation precautions interventions to prevent this potential route of disease transmission are urgent to protect the lives of workers in danger and the consequences that threaten public health. (14). One useful tool for estimating human health risks from exposure to pathogens in various environmental matrices is a quantitative microbiological risk assessment (QMRA) and was used to assess health risks from drinking water, recycled water, bioaerosols, and sewage (15) so that QMRA can be used to assess the probability of harmful effects of SARS-CoV-2 associated with wastewater exposure (8). A recent study was done at the WWTP in Isfahan, Iran (12), SARS-CoV-2 was detected in 37.5\% (9 of 24 ) wastewater samples with a concentration about $10^{4}$ genomic copies $\mathrm{L}^{-1}$. Coronavirus RNA was also detected in 6/15 (40\%) of air samples. Analysis of QMRA showed a relatively high risk of infection with SARS-CoV-2 in WWWs exposed to viral aerosols. The estimated annual infection risk ranged from $1.1 \times 10^{-2}$ to $2.3 \times 10^{-2}$ per person per year (PPPY) for workers at WWTP, which was higher than the WHO recommended reference level ( $\left.10^{-3} \mathrm{pppy}\right)$. QMRA studies identify the unique features of SARS-CoV-2 that may raise concerns about current regulations and approaches to protecting public health (8).

SARS-CoV-2 preventive and control measures should be taken in any part of WWTPs where viral particles are likely to be transmitted (16). To reduce direct contact and the risk of COVID-19 infection, prevention and control measures, such as the appropriate use of PPE when workers at WWTPs come into contact with wastewater treatment facilities and raw wastewater can be effective; particularly for workers who come into contact with processes for producing aerosols and droplets in suspension (12). Employees must be encouraged to wear protective clothing that includes gloves, protective outerwear, safety goggles, face mask, or face shield. The use of the N95 respirator is highly effective in filtering airborne particles such as bioaerosols (17). Workers should wash their hands regularly, especially before eating and drinking, avoid touching their eyes, mouth, and nose with unwashed hands. Technical measures should be taken to reduce the production of aerosols and droplets in different parts of the WWTP and to cover bioaerosol production processes. Reducing working hours for operators can also reduce the risk of SARSCoV-2 infection $(6,10)$. Operators must also make sure that surfaces exposed to liquids and droplets that pose a risk of viral contamination are kept clean before changing shifts (17). Overall, agencies should follow U.S. recommendations from the Occupational Safety and Health Administration (OSHA) and local occupational health and safety organizations depending on the conditions in their local establishments (10).

\section{Conclusions}

The recent global outbreak of SARS-CoV-2 has highlighted the lack of knowledge about SARS-CoV-2 in the field of wastewater and WWTPs. Based on studies of SARS-CoV-2 in wastewater, confirmation of the presence of SARS-CoV-2 in wastewater raises the question of transfer of SARS-CoV-2 through wastewater, particularly in WWTPs, because workers at WWTP can be among the most susceptible groups to exposure to SARS-CoV-2. The data indicate the need for additional studies on the survival time of the virus under various environmental conditions in WWTPs, as well as the efficiency of individual protection methods. However, because of the respiratory nature of the virus and the sewage treatment processes that may produce aerosols that may carry viral contamination, workers in WWTPs must use maximum PPE and implement CPE to minimize the risk of COVID-19 infection in WWTPs.

\section{Footnotes}

Authors' Contribution: All authors made equal contributions to the writing of the manuscript.

Conflict of Interests: The authors declare that they have no conflict of interests.

Funding/Support: This paper was self-funded by the authors.

\section{References}

1. Hossini H, Atashkar S, Massahi T. Face mask consumption and medical waste generation during the COVID-19 pandemic in Iran: Challenges and problems. Int J Health Life Sci. 2021;7(3). doi: 10.5812/ijhls.115046.

2. Kitajima M, Ahmed W, Bibby K, Carducci A, Gerba CP, Hamilton KA, et al. SARS-CoV-2 in wastewater: State of the knowledge and research needs. Sci Total Environ. 2020;739:139076. doi: 10.1016/j.scitotenv.2020.139076. [PubMed: 32758929]. [PubMed Central: PMC7191289].

3. Haramoto E, Malla B, Thakali O, Kitajima M. First environmental surveillance for the presence of SARS-CoV-2 RNA in wastewater and river water in Japan. Sci Total Environ. 2020;737:140405. doi: 10.1016/j.scitotenv.2020.140405. [PubMed: 32783878]. [PubMed Central: PMC7305903]

4. Ahmed W, Angel N, Edson J, Bibby K, Bivins A, O’Brien JW, et al. First confirmed detection of SARS-CoV-2 in untreated wastewater in Australia: A proof of concept for the wastewater surveillance of COVID-19 in the community. Sci Total Environ. 2020;728:138764. doi: 10.1016/j.scitotenv.2020.138764. [PubMed: 32387778]. [PubMed Central: PMC7165106].

5. Amoah ID, Kumari S, Bux F. Coronaviruses in wastewater processes: Source, fate and potential risks. Environ Int. 2020;143:105962. doi: 10.1016/j.envint.2020.105962. [PubMed: 32711332]. [PubMed Central: PMC7346830]. 
6. Brisolara KF, Maal-Bared R, Sobsey MD, Reimers RS, Rubin A, Bastian RK, et al. Assessing and managing SARS-CoV-2 occupational health risk to workers handling residuals and biosolids. Sci Total Environ. 2021;774:145732. doi: 10.1016/j.scitotenv.2021.145732. [PubMed: 33611008]. [PubMed Central: PMC7869681].

7. Wu Y, Guo C, Tang L, Hong Z, Zhou J, Dong X, et al. Prolonged presence of SARS-CoV-2 viral RNA in faecal samples. Lancet Gastroenterol Hepatol. 2020;5(5):434-5. doi: 10.1016/S2468-1253(20)30083-2. [PubMed: 32199469]. [PubMed Central: PMC7158584].

8. Zaneti RN, Girardi V, Spilki FR, Mena K, Westphalen APC, da Costa Colares ER, et al. Quantitative microbial risk assessment of SARS CoV-2 for workers in wastewater treatment plants. Sci Total Environ. 2021;754:142163. doi: 10.1016/j.scitotenv.2020.142163. [PubMed 32911141]. [PubMed Central: PMC7468340].

9. Foladori P, Cutrupi F, Segata N, Manara S, Pinto F, Malpei F, et al. SARS-CoV-2 from faeces to wastewater treatment: What do we know? A review. Sci Total Environ. 2020;743:140444. doi: 10.1016/j.scitotenv.2020.140444. [PubMed: 32649988]. [PubMed Central: PMC7311891].

10. World Health Organization; United Nations Children's Fund. Water, sanitation, hygiene and waste management for COVID-19: technical brief, 03 March 2020. Geneva: World Health Organization; 2020. Report No.: WHO/2019-NcOV/IPC_WASH/2020.1.

11. Noble RT, Fuhrman JA. Virus decay and its causes in coastal waters. Appl Environ Microbiol. 1997;63(1):77-83. doi: 10.1128/aem.63.1.77-
83.1997. [PubMed: 16535501]. [PubMed Central: PMC1389091].

12. Gholipour S, Mohammadi F, Nikaeen M, Shamsizadeh Z, Khazeni A, Sahbaei Z, et al. COVID-19 infection risk from exposure to aerosols of wastewater treatment plants. Chemosphere. 2021;273:129701. doi: 10.1016/j.chemosphere.2021.129701. [PubMed: 33517118]. [PubMed Central: PMC7825974].

13. Fears AC, Klimstra WB, Duprex P, Hartman A, Weaver SC, Plante KC, et al. Comparative dynamic aerosol efficiencies of three emergent coronaviruses and the unusual persistence of SARS-CoV-2 in aerosol suspensions. medRxiv. 2020. doi: 10.1101/2020.04.13.20063784. [PubMed: 32511433]. [PubMed Central: PMC7217084].

14. Heller L, Mota CR, Greco DB. COVID-19 faecal-oral transmission: Are we asking the right questions? Sci Total Environ. 2020;729:138919. doi: 10.1016/j.scitotenv.2020.138919. [PubMed: 32353720]. [PubMed Central: PMC7182518].

15. Haas CN, Rose JB, Gerba CP.Quantitative Microbial RiskAssessment. John Wiley \& Sons; 2014.

16. Liu D, Thompson JR, Carducci A, Bi X. Potential secondary transmission of SARS-CoV-2 via wastewater. Sci Total Environ. 2020;749:142358. doi: 10.1016/j.scitotenv.2020.142358. [PubMed: 33370879]. [PubMed Central: PMC7490247].

17. WHO. Water, W. and H.J.R.W. Sanitation, Waste Management for SARS-CoV-2, the Virus That Causes COVID-19. 2020. Available from: https://www.who.int/publications/i/item/WHO-2019-nCoV-IPCWASH-2020.4. 